\title{
Morfologia externa das ninfas e adultos de Ctenarytaina spatulata Taylor (Hemiptera, Psyllidae)
}

\author{
Dalva Luiz de Queiroz Santana ${ }^{1} \&$ Keti Maria Rocha Zanol ${ }^{2}$
}

\begin{abstract}
${ }^{1}$ Embrapa-Florestas, Estrada da Ribeira Km 111, 83411-000 Colombo-PR, Brasil. dalva@enpf.embrapa.br
${ }^{2}$ Departamento de Zoologia, Universidade Federal do Paraná, Caixa Postal 19020, 81531-990 Curitiba-PR, Brasil. Bolsista do CNPq. kzanol@ufpr.br
\end{abstract}

\begin{abstract}
External morphology of adults and nymphs of Ctenarytaina spatulata Taylor (Hemiptera, Psyllidae). Ctenarytaina spatulata Taylor, 1997 was introduced in Brazil in the 1990 in eucalyptus plantations. Due to the importance of the C. spatulata as an eucalyptus pest, this research was developed in order to study the external morphology of adults and nymphs, with special detail on the $5^{\text {th }}$ instar nymphs. Considerable differences were observed among the nymphal instars, mainly in respect to size and characters of the antennae, the legs and the apex of the abdomen. The adult external morphology was presented with details of the wing veins, the characteristics of the legs, antennae and the genitalia.
\end{abstract}

KEYWORDS. Ctenarytaina spatulata, eucalyptus pest, morphology, Psyllidae.

RESUMO. Morfologia externa das ninfas e adultos de Ctenarytaina spatulata Taylor (Hemiptera, Psyllidae). Ctenarytaina spatulata Taylor, 1997 foi introduzida no Brasil na década de 1990 em plantios de eucalipto. Devido a importância de C. spatulata como praga de eucalipto, o objetivo desta pesquisa foi estudar a morfologia externa do adulto e das ninfas, com detalhamento da ninfa de $5^{\circ}$ ínstar. Foram observadas diferenças marcantes entre os ínstares, principalmente quanto ao tamanho e os caracteres das antenas, das pernas e do ápice do abdômen. A morfologia externa dos adultos foi apresentada com detalhamento da venação, das características das pernas e da terminália.

PALAVRAS-CHAVE. Ctenarytaina spatulata, morfologia, praga do eucalipto, Psyllidae.

Os estudos morfológicos têm como objetivo caracterizar os organismos para sua identificação, classificação e estudos filogenéticos. Os insetos geralmente são descritos a partir de exemplares adultos, sendo os caracteres dos jovens acrescidos como detalhes à descrição da espécie.

Para os Psylloidea (Hemiptera), a classificação é baseada quase que exclusivamente em caracteres de adultos coletados no Hemisfério Norte, em regiões de clima temperado (Tuthill, 1943; Hodkinson, 1974, 1988). White \& Hodkinson (1985), ao estudarem os caracteres morfológicos das ninfas de 303 espécies observaram uma grande variação e apresentaram e discutiram os caracteres mais adequados para estudos taxonômicos; apresentaram cladogramas e chaves para as famílias, subfamílas e alguns gêneros e, sugeriram, também, relacionamentos filogenéticos entre os grupos estudados.

Após os estudos de White \& Hodkinson (1985) e com a descrição de novas espécies na região tropical, Burckhardt (1994) propôs uma nova classificação dividindo os Psylloidea em seis subfamílias: Psyllidae (incluindo Aphalaridae e Spondyliaspididae), Calophydae, Phacopteronidae, Carsidaridae, Homotomidae e Triozidae.

$\mathrm{Na}$ descrição original de Ctenarytaina spatulata Taylor, 1997 foram utilizados alguns caracteres dos adultos e para a ninfa de $5^{\circ}$ ínstar a descrição foi baseada no ápice do adbômen. Posteriormente, Burckhardt et al. (1999) adicionaram novos caracteres num quadro comparativo entre $C$. spatulata e $C$. eucalypti (Maskell, 1890), sendo esta a espécie mais estudada do gênero.

Devido à importância de C. spatulata como praga de eucalipto o presente trabalho tem como objetivo estudar a morfologia externa dos adultos e descrever as ninfas, com detalhamento da ninfa de $5^{\circ}$ ínstar, acrescentando novos caracteres às descrições anteriores.

\section{MATERIAL E MÉTODOS}

Para a observação dos caracteres morfológicos, foram coletadas partes apicais de ramos de Eucalyptus grandis, E. urophylla e híbridos E. grandis x E. urophylla contendo ovos, ninfas e adultos de C. spatulata em Colombo, PR, São Miguel Arcanjo, SP e Mogi-Guaçu, SP. Alguns exemplares foram conservados em álcool $70 \%$ e outros foram utilizados para infestar mudas de E. grandis em casa de vegetação e no laboratório com objetivo de observar os espécimens vivos.

As mensurações, foram realizadas com auxílio de ocular micrométrica, acoplada ao microscópio estereoscópico Olympus BX50 e as ilustrações a partir de material preparado em lâminas com glicerina líquida e, com auxílio de câmara clara acoplada ao microscópio Wild M20. As ninfas foram descritas observando-se os critérios sugeridos por White \& Hodkinson (1985).

\section{RESULTADOS E DISCUSSÃO}

Ovos. São elípticos, afilados na extremidade superior, em forma de uma gota (Fig. 1A). Imediatamente após a postura são branco-translúcidos, tornando-se gradativamente amarelados até a eclosão, quando são totalmente amarelo com 


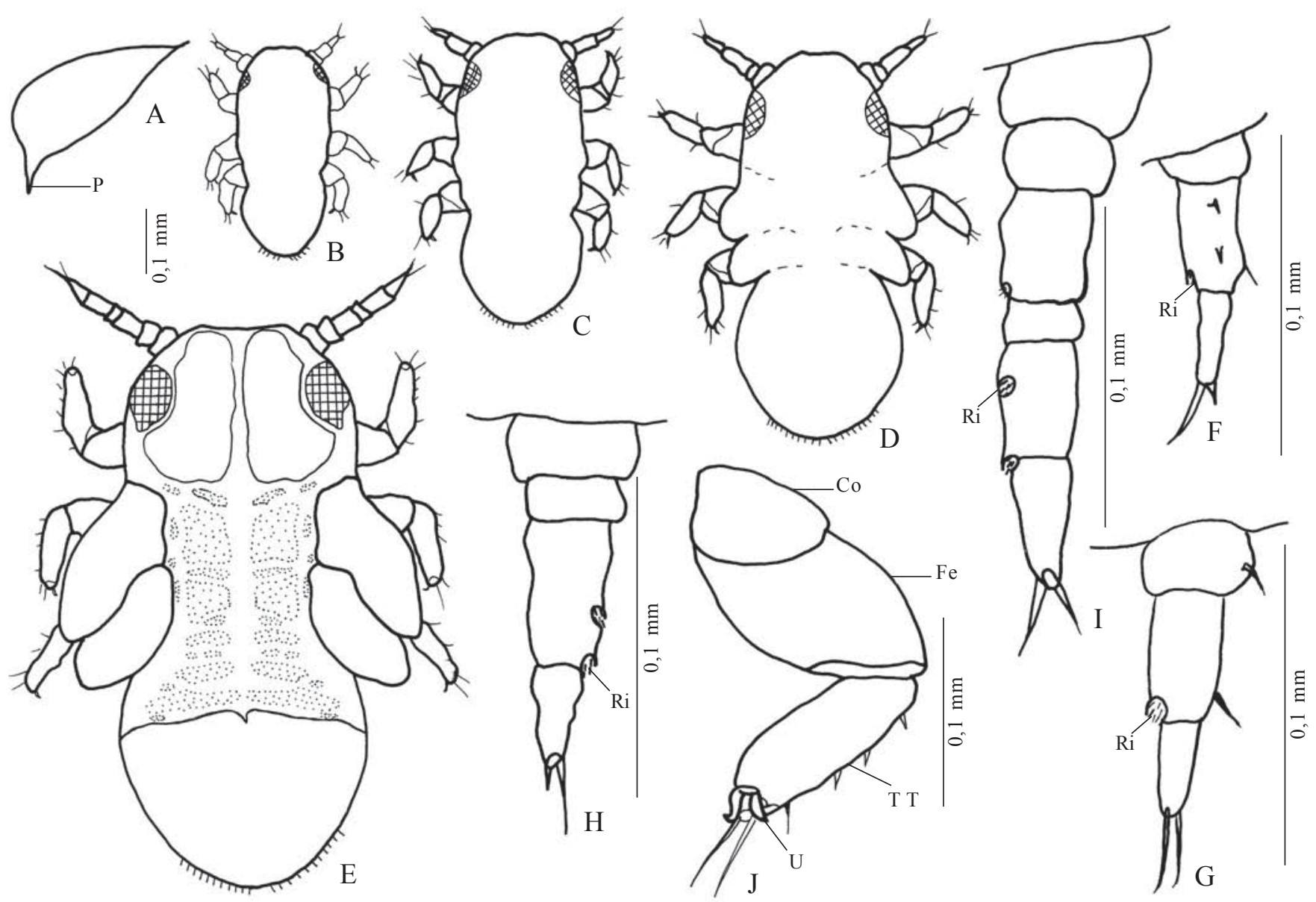

Fig. 1. Ctenarytaina spatulata Taylor, 1997. A, ovo; B - E. ninfas: B, $1^{\circ}$ ínstar; C, $2^{\circ}$ ínstar; D, $3^{\circ}$ ínstar; E, $4^{\circ}$ ínstar; F - I. antenas: F, $1^{\circ}$ ínstar; G, $2^{\circ}$ ínstar; H, $3^{\circ}$ ínstar; I, $4^{\circ}$ ínstar; J, perna metatorácica da ninfa de $4^{\circ}$ ínstar. Co. coxa; Fe. fêmur; P. pedúnculo; Ri. rinária; TT. tíbia-tarso; U. unha.

as manchas ocelares vermelhas na parte mais afilada. Possuem um pedúnculo hialino, curto, fino e pouco perceptível, que sai da parte inferior lateral do ovo que fica inserido na planta.

Comprimento aproximado de $0,28 \mathrm{~mm} \mathrm{e} 0,13 \mathrm{~mm}$ de largura, na parte mais globosa.

Ninfas. Em todos os ínstares apresentam o corpo achatado dorsoventralmente, sendo possível observar a linha de sutura, principalmente próximo ao processo da muda. Segundo Hodkinson (1974), a forma achatada tornam-as muito susceptíveis à perda de água, principalmente em altas temperaturas e, este é um fator importante que contribui para o controle populacional.

O aparelho bucal é típico de Sternorrhyncha, ou seja, o ápice do clípeo estende-se até o mesotórax; lábio com dois artículos sendo o apical marrom-escuro; estiletes bastante longos e finos (Fig. 2A).

Primeiro ínstar. Corpo totalmente amarelo, exceto pelos pequenos olhos vermelhos (Fig. 1B). Antenas com três artículos e duas cerdas apicais; o primeiro artículo é mais largo do que longo e os dois apicais mais longos do que largos; no artículo II observa-se no ápice uma pequena rinária (Fig. 1F); artículo apical marrom-escuro. Pernas com coxa, fêmur e tíbiatarso com unhas e duas longas cerdas apicais; tarso não aparente. Abdômen arredondado com cinco setas lanceoladas de cada lado da abertura anal.

Comprimento total do corpo, em média $0,37 \mathrm{~mm}$; a maior largura da cabeça, em média $0,16 \mathrm{~mm}$; largura na região dos futuros brotos alares em média $0,17 \mathrm{~mm}$ e o comprimento total da antena de $0,06 \mathrm{~mm}$.

Segundo ínstar. Semelhante na forma e coloração a ninfa de primeiro ínstar, porém, já se observa os brotos alares como pequenas protuberâncias do tórax (Fig. 1C). Antenas com três artículos e duas cerdas apicais; o primeiro artículo é mais curto e os dois últimos mais longos do que largos; no artículo II observa-se nitidamente uma rinária apical (Fig. 1G); artículo apical marrom-escuro. Pernas com coxa, fêmur e tíbia-tarso com unhas e duas longas cerdas apicais; tarso não aparente. Abdômen arredondado com oito setas lanceoladas de cada lado da abertura anal.

Comprimento total do corpo, em media $0,52 \mathrm{~mm}$; largura máxima da cabeça, em média $0,21 \mathrm{~mm}$; largura na região dos brotos alares é em média $0,24 \mathrm{~mm}$ e o comprimento das antenas é de $0,09 \mathrm{~mm}$. 


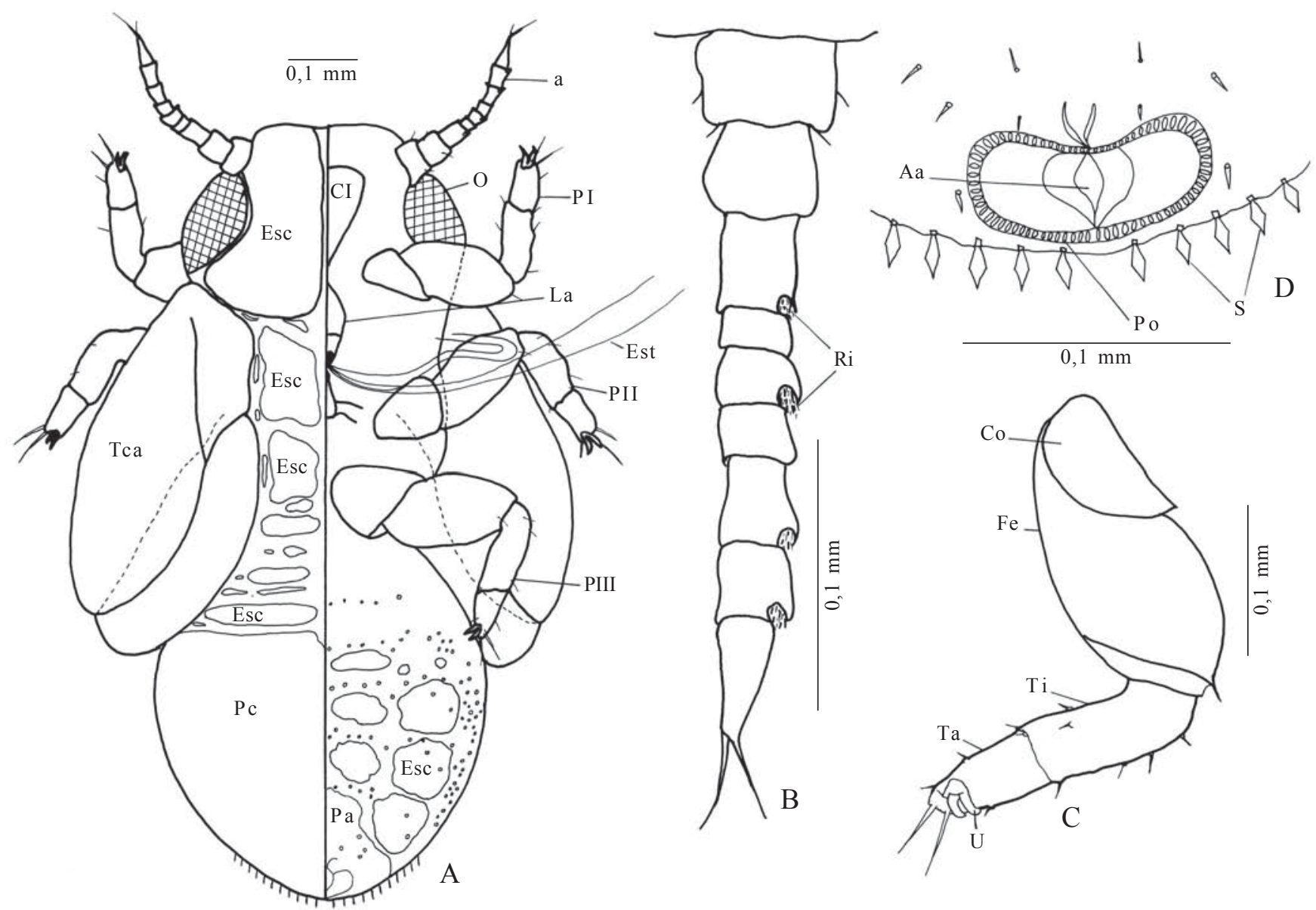

Fig. 2. Ctenarytaina spatulata Taylor, 1997. A, ninfa de $5^{\circ}$ ínstar; B, antena; C, perna metatorácica; D, ápice do abdômen, ventral. a. antena; Aa. abertura anal; Cl. clípeo; Co. coxa; Esc. esclerito; Est. estilete; Fe. fêmur; La. lábio; O. olho; Pa. placa anal; Pc. placa caudal; PI. perna protorácica; PII. perna mesotorácica; PIII. perna metatorácica; Po. poro anal; Ri. rinária; S. seta lanceolada; Ti. tíbia; Ta. tarso; Tca. teca alar anterior.; U. unha.

Terceiro ínstar. Corpo amarelo com às ninfas de $1^{\circ}$ e $2^{\circ}$ ínstares, com brotos alares evidentes (Fig. 1D); alguns espécimes apresentam manchas marrom-claras que vão escurecendo gradativamente até o marrom-escuro. Antenas com quatro artículos e duas cerdas apicais; os dois primeiro artículos são mais curtos e os dois apicais mais alongados; artículo III com duas rinárias, sendo uma apical e outra subapical (Fig. 1H); artículo apical marrom-escuro. Pernas com coxa, fêmur e tíbia-tarso com unhas e duas longas cerdas; tarso não aparente. Abdômen arredondado com 10 setas lanceoladas de cada lado da abertura anal.

Comprimento total do corpo em média $0,68 \mathrm{~mm}$; largura máxima da cabeça, em média $0,27 \mathrm{~mm}$; largura na região dos brotos alares é em média $0,36 \mathrm{~mm}$; comprimento das antenas de $0,13 \mathrm{~mm}$.

Quarto ínstar. Corpo amarelo com escleritos marrons (Fig. $1 \mathrm{E})$; logo após a muda apresentam coloração totalmente amarela. Antenas com seis artículos e duas cerdas apicais; os dois primeiros artículos são mais curtos e os dois apicais mais alongados; artículos I, II e IV são mais largos do que longos e os demais mais longos do que largos; no artículo III observase uma rinária apical; no artículo $\mathrm{V}$ observam-se duas rinárias sendo uma apical e outra subapical (Fig. 1I); coloração marromclara com artículo apical marrom-escuro. Tecas alares desenvolvidas e bem visíveis. Pernas (Fig. 1J) com coxa, fêmur e tíbia-tarso com unhas e duas longas cerdas; tarso não aparente; coloração marrom-clara com tíbia-tarso marromescura. Abdômen arredondado com 11 setas lanceoladas de cada lado da abertura anal.

Comprimento total do corpo em média $0,86 \mathrm{~mm}$; largura máxima da cabeça, em média $0,33 \mathrm{~mm}$; largura na região dos tecas alares é em média $0,50 \mathrm{~mm}$; comprimento das antenas de $0,19 \mathrm{~mm}$.

Quinto ínstar. Corpo amarelo com escleritos marrons. Cabeça e protórax fundidos, formando, segundo White \& Hodkinson (1985), o cefaloprotórax, onde se observam dois escleritos que se estendem desde a margem anterior da cabeça até a coxa protorácica (Fig. 2A). As antenas originam-se na margem da cabeça com nove artículos, de comprimento variável e duas cerdas apicais; nos artículos III, V, VII e VIII observa-se uma rinária apical (Fig. 2B); coloração marrom-clara sendo os três artículos apicais marrom-escuros.

Tergo mesotorácico com $2+2$ pequenos escleritos livres, junto ao cefaloprotórax, $2+2$ escleritos dorsais e $1+1$ escleritos 

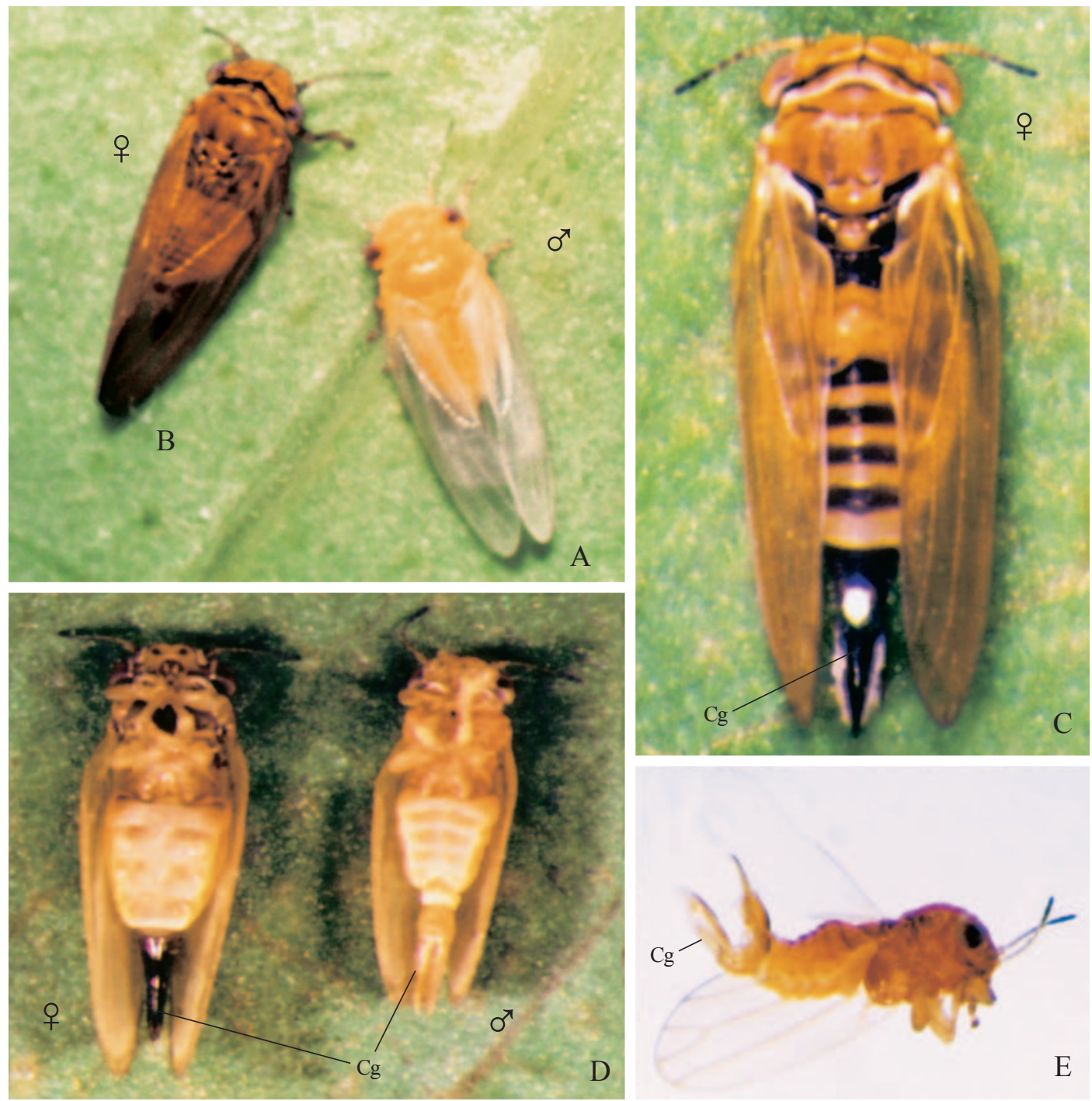

Fig. 3. Ctenarytaina spatulata Taylor, 1997. A, macho recém emergido; B, fêmea; C, fêmea com abdômen listrado; D, fêmea e macho, vista ventral; E, macho, vista lateral. $\mathrm{Cg}$. cápsula genital.

laterais. Tergo metatorácico com $2+2$ escleritos dorsais e $1+1$ escleritos laterais (Fig. 2A). Tecas alares bem desenvolvidas; as anteriores começam abaixo da linha dos olhos sem formar lóbulo humeral (Fig. 2A). Pernas (Fig. 2C) amareladas com coxa, fêmur, tíbia e tarso; neste com unhas bem esclerotinizadas, duas longas cerdas e arólio. Apenas neste ínstar há nítida diferenciação do tarso que apresenta coloração marromescura.

Abdômen, em vista dorsal, com os primeiros segmentos delimitados através de escleritos livres dispostos em $1+1$ por segmento, quando se fundem formando a placa caudal. Em vista ventral, observa-se 1+1 escleritos livres e uma série de pequenas cerdas nos segmentos à frente da placa anal (Fig. 2A); ápice arredondado margeado por 11 setas lanceoladas de cada lado da abertura anal; abertura esta circundada por um anel de poros anais simples, de forma ovalada (Fig. 2D). Não foram observados poros adicionais ao longo da margem caudal.
Comprimento do corpo em média $1,35 \mathrm{~mm}$; largura máxima da cabeça, em média $0,48 \mathrm{~mm}$; largura na região dos tecas alares em média $0,79 \mathrm{~mm}$; comprimento das antenas em média $0,32 \mathrm{~mm}$.

Taylor (1977), na descrição da espécie, observou no ápice abdominal 22 setas lanceoladas quantidade esta também observada em alguns espécimes, porém este número não é constante, pois observa-se em alguns 20 setas sendo 10 de cada lado da abertura anal.

Segundo White \& Hodkinson (1985), uma característica das ninfas de $5^{\circ}$ ínstar de Psyllinae é a ausência de um lobo proeminente anterior nas tecas alares anteriores o que foi comprovado em C. spatulata. Nesse mesmo trabalho observam que as ninfas com 10 artículos antenais possuem rinária nos artículos IV, VI, VIII e IX e que as ninfas com um número menor de artículos, às vezes, apresentam finas suturas que podem sugerir a posição de uma futura divisão da antena. Em $C$. spatulata observa-se nitidamente nove artículos com a posição 

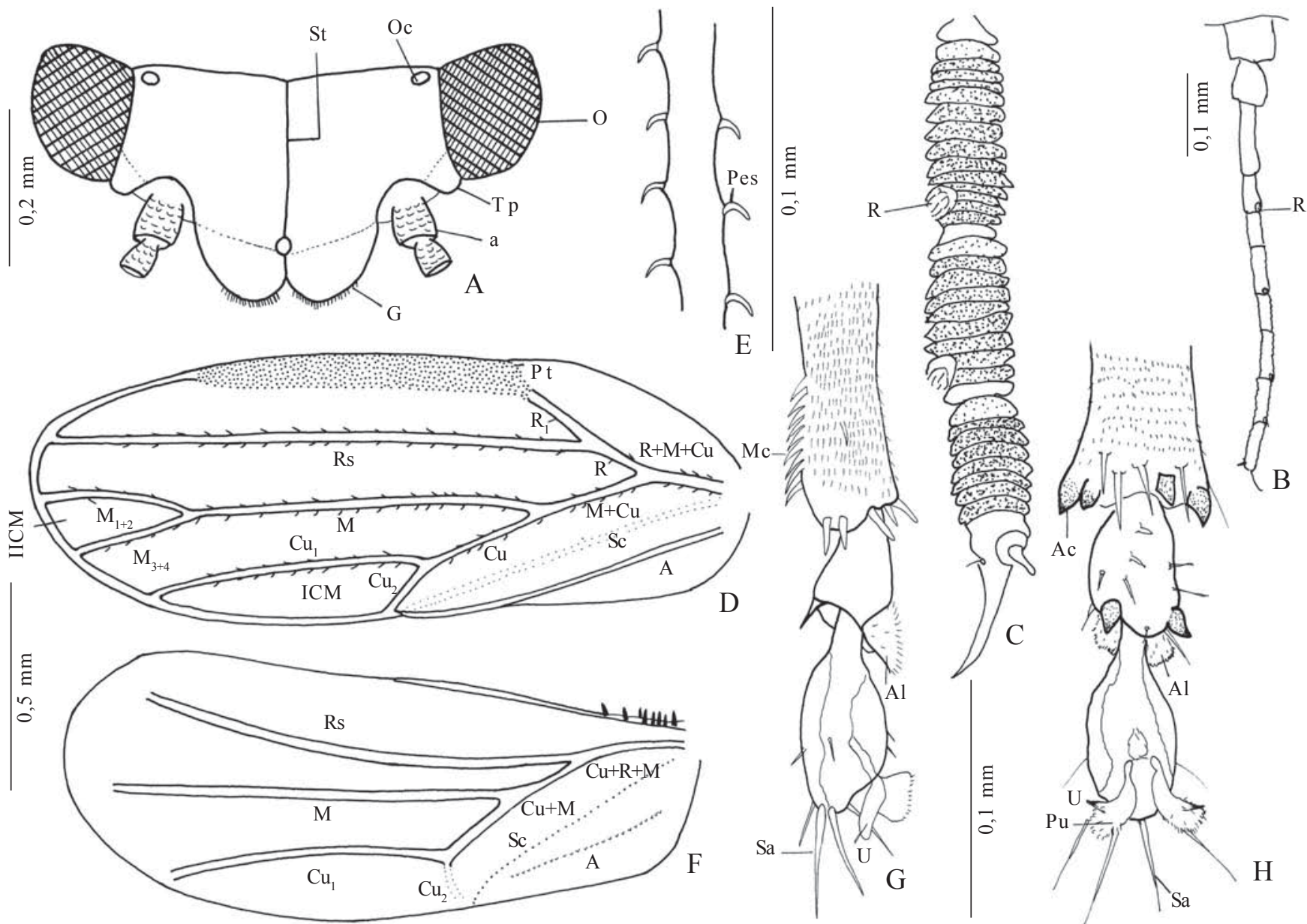

Fig. 4. Ctenarytaina spatulata Taylor, 1997. A, cabeça, dorsal; B, antena; C, ápice da antena; D, asa anterior; E, detalhe da veia M; F, asa posterior; G, ápice da mesotíbia; H, ápice da metatíbia. A. veia anal; Al. almofada tarsal; Cu. veia cubital; Ac. acúleos apicais; G. gena; ICM. $1^{\text {a }}$ célula apical; IICM. 2a célula apical; M. veia média; Mc. macrocerdas; O. olho; Oc. ocelo; Pes. projeções espiniformes; Pt. pterostigma; Pu. pulvilo R. veia radial; Ri. rinária; Rs. veia setor radial; Sa. setas apicais; Sc. sutura claval; St. sutura coronal; Tp. tubérculo pré-ocular; U. unha.

das rinárias diferente das observadas por White \& Hodkinson (1985).

Burckhardt et al. (1999) observaram que próximo ao ápice do abdômen pode ocorrer uma pequena quantidade de poros adicionais, quando comparado com C. eucalypti que apresenta uma grande quantidade destes poros. Nos espécimes estudados não foi constatado nenhum poro adicional.

Pinzón et al. (2002) caracterizaram sucintamente todos os ínstares de C. eucalypti e nesta observaram, como em $C$. spatulata, brotos alares nas ninfas de $2^{\circ}$ ínstar. Em ambas, pode-se, também, em todos os ínstares observar os olhos vermelhos.

Adultos. Os machos e fêmeas adultos são bastante semelhantes, a não ser pela cápsula genital e pelo tamanho levemente menor dos machos (Fig. 3A-E). Imediatamente após a emergência apresentam coloração amarela-clara, com asas transparentes e esbranquiçadas (Fig. 3A); logo depois começam a escurecer passando para uma coloração alaranjada (Fig. 3B), com pequenas manchas marrons no tórax e no abdômen; estas, normalmente em faixas, dando um aspecto listrado (Fig. 3C).
A cabeça, em vista dorsal, é mais larga do que longa com tubérculo pré-ocular proeminente; coroa completamente dividida pela sutura coronal; ocelos em número de três sendo dois laterais, na margem posterior da coroa, visíveis de cima e um ocelo mediano, anterior, delimitando a fronte; olhos arredondados e proeminentes; genas com ápices arredondados e uma coroa de cerdas apicais (Fig. 4A, 4C). Antenas com 10 artículos sendo os sete artículos distais semelhantes quanto a forma e duas cerdas apicais (Fig. 4B); artículos IV, VI, VIII e IX com uma rinária apical; superfície, exceto no escapo e pedicelo, ornada por pequenos anéis, que variam em número de acordo com o tamanho do artículo (Fig. 4C); coloração amarelada, escurecendo gradativamente para o ápice, com os três últimos artículos visivelmente mais escuros.

Os escleritos e suturas do tórax de C. spatulata são congruentes com a descrição de Matsuda (1965: 250-261, Figs. 106A; 107A).

As asas anteriores (Fig. 4D) são transparentes com fina granulação. As veias média (M) e cubital $(\mathrm{Cu})$ estão fusionadas com a radial ( $\mathrm{R}$ ); estas bifurcam-se formando $\mathrm{R} \mathrm{e} \mathrm{M}+\mathrm{Cu}$. A R continua em uma pequena $\mathrm{R}_{1}$ enquanto que a setor radial (Rs) alcança o ápice. A área entre R e a margem costal denomina-se 

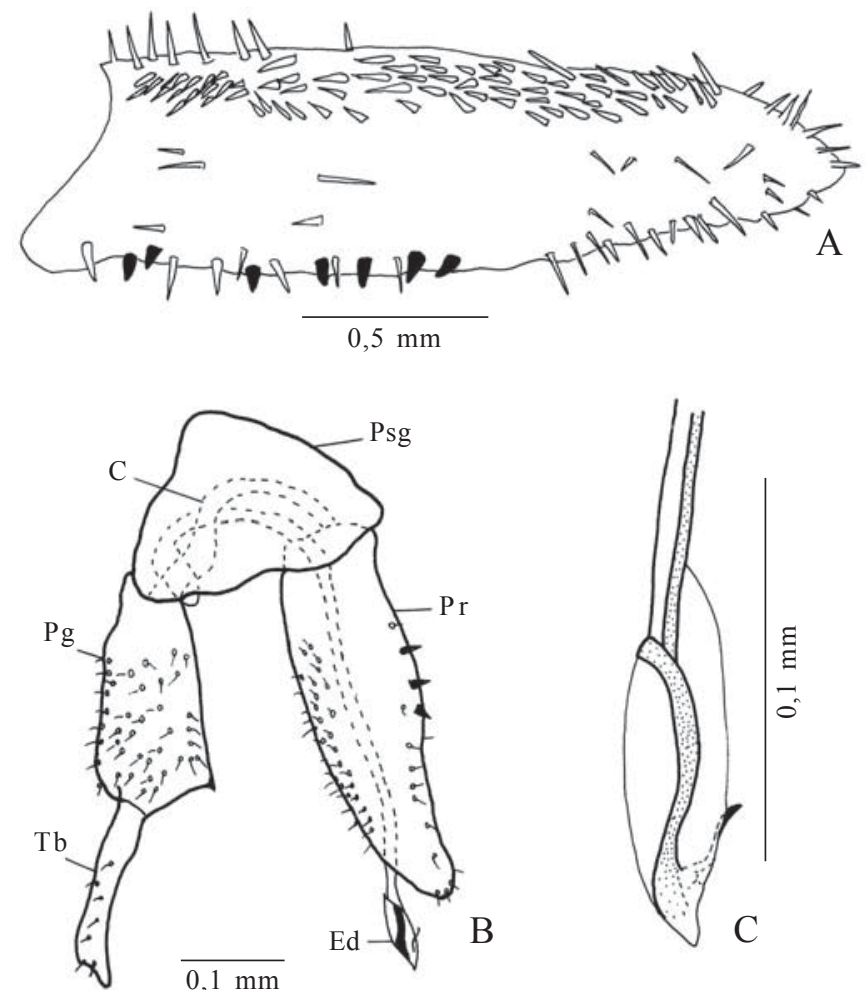

Fig. 5. Ctenarytaina spatulata Taylor, 1997. Terminália do macho. A, parâmero; B, terminália, vista lateral; C, ápice do edeago. C. conetivo; Ed. edeago; Pg. pigóforo; Pr. parâmero; Psg. placa subgenital; Ta. tubo anal.

pterostigma e geralmente apresenta uma granulação mais densa. A Cu bifurca-se em $\mathrm{Cu}_{1}$ e $\mathrm{Cu}_{2}$ formando a $1^{\mathrm{a}}$ célula marginal. A $\mathrm{M}$ bifurca-se, no ápice, em $\mathrm{M}_{1+2} \mathrm{e}_{3+4}$, formando a $2^{\mathrm{a}}$ célula marginal. A sutura claval é demarcada por uma área transparente sem nenhuma pigmentação. No clavo observase somente uma veia anal (A). As veias, exceto a A, apresentam projeções espiniformes laterais (Fig. 4E).

Asas posteriores (Fig. 4F) transparentes, mais granulada $\mathrm{e}$ menos pigmentada do que as anteriores. As veias $\mathrm{Cu}, \mathrm{M}$ e $\mathrm{R}$ fundem-se, na base, formando o ramo $\mathrm{Cu}+\mathrm{M}+\mathrm{R}$. Após a bifurcação, a R continua como Rs e a $\mathrm{M}$ como um único ramo até próximo ao ápice, quando tornam-se evanescentes. $\mathrm{A} \mathrm{Cu}$ bifurca-se em $\mathrm{Cu}_{1}$ e $\mathrm{Cu}_{2}$, sendo esta levemente delimitada.

Pernas com arículos típicos. Tíbias mesotorácicas (Fig. 4G) com uma fileira de macrocerdas no terço apical. Ápice das tíbias posteriores (Fig. 4H) com uma coroa de cinco processos aculeiformes; ápice do tarsômero basal com um acúleo da cada lado e tarsômero apical com um par de unhas e pulvilo (Fig. $4 \mathrm{H})$. Entre os tarsômeros observa-se uma área membranosa com pequenas cerdas denominadas "almofada tarsal" (Figs. $4 \mathrm{G}, 4 \mathrm{H})$.

Os escleritos do abdômen de C. spatulata (tergitos, laterotergitos e esternitos) são congruentes com Crawford (1914: 15-16, pl.3).

Os parâmetros biométricos observados em C. spatulata foram semelhantes aos obtidos por Taylor (1997).

Burckhardt et al. (1999: 7), no desenho da cabeça de $C$. spatulata ilustraram o ocelo anterior numa área mais ou menos triangular e uma "sutura" que se estende desde esta área até os ocelos posteriores. Não se observou esta área e "sutura", em nenhum dos espécimes analisados nem na ilustração da descrição original.

As tíbias mesotorácicas apresentam uma fileira de macrocerdas, próxima ao ápice, que é um caráter diagnóstico do gênero. Tuthill \& Taylor (1955) denominaram-nas de pente de pequenas setas e Burckhardt et al. (1999) de pente de cerdas. Optou-se pela denominação de macrocerdas para diferenciálas das demais cerdas e setas que ocorrem em outras estruturas. Nas tíbias metatorácicas observa-se cinco processos aculeiformes que foram denominadas por Tuthill \& Taylor (1955) e por Taylor (1997) como setas pretas. Optou-se pelo termo aculeiforme devido a seu aspecto.

Crawford (1914), denominou as células apicais delimitadas por $\mathrm{Cu}_{1}$ e $\mathrm{Cu}_{2} \mathrm{e}, \mathrm{M}_{1+2}$ e $\mathrm{M}_{3+4}$ de células marginais, terminologia adotada neste trabalho. Alguns autores consideram a sutura claval como $\mathrm{Cu}_{2}$ enquanto $\mathrm{Cu}_{1}$ é dividida em $\mathrm{Cu}_{1 \mathrm{a}}$ e $\mathrm{Cu}_{1 \mathrm{~b}}$ (Richards \& Davies, 1977; Borror et al., 1981); Burckhardt et al. (1999), embora não tenham feito nenhuma indicação da venação, na tabela comparativa de C. spatulata e C. eucalypti, fazem menção quanto à forma de $\mathrm{Cu}_{1 b}$.

Terminália. Macho. Cápsula genital de coloração semelhante ao restante do corpo (Fig. 3D), ou levemente mais escura, voltada para cima, tocando as asas (Fig. 3E). Pigóforo mais ou menos retangular com inúmeras cerdas na superfície e um processo dentiforme, ventro-apical. Tubo anal estreito, retangular, quase tão longo quanto o pigóforo; ápice oblíquo. Placa subgenital triangular. Conetivo linear com o formato de uma fita (Fig. 5B). Parâmeros triangulares com as bordas sinuosas; borda interna com inúmeras cerdas marginais e processos espiniformes esclerotinizadas; borda externa com inúmeras setas, na superfície, ao longo da margem e cerdas marginais (Figs. 5A, B). Edeago tubular, voltado para cima, mais longo que o pigóforo (Fig. 5B); ápice alargado, mais ou menos elíptico, menos esclerotinizado do que a haste do edeago, com um pequeno processo, voltado para trás e para baixo (Fig. 5C).

Terminália. Fêmea. Cápsula genital marrom-escura. Pigóforo triangular com várias cerdas, na superfície (Figs. 6A, B); abertura anal de forma elíptica rodeada por um círculo de poros anais dispostos em duas fileiras, próximo a base (Fig. 6C); aproximadamente na metade apical com duas fileiras de pequenas setas lanceoladas (Fig. 6D). Placa subgenital triangular, levemente menor que o pigóforo (Fig. 6E). Ovipositor com três pares de valvas (Figs. 6E, F); a valva III ou dorsal é membranosa com ápice arredondado e textura rugosa; a valva I ou ventral é um pouco mais longa do que a dorsal, com ápice curvo e levemente serreado; valva II ou média, geralmente oculta pelas demais, se apresenta fusionada em quase toda sua extensão, une-se à valva dorsal por uma barra esclerotinizada.

Ossiannilson et al. (1970), Taylor (1977) e Burckhardt et al. (1999), denominaram o pigóforo de "proctiger". O termo "proctiger" na realidade significa o tubo anal onde, no ápice, 


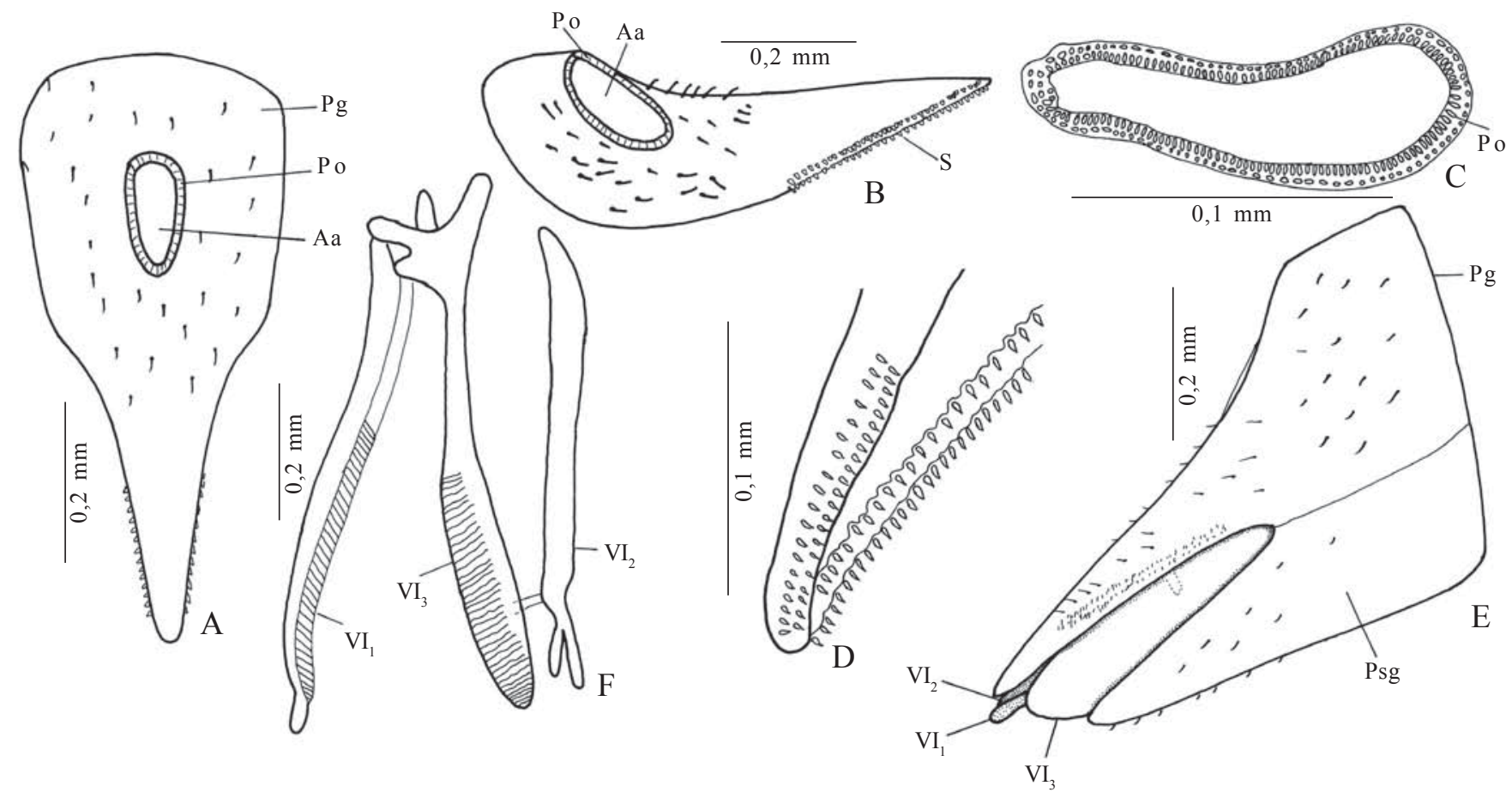

Fig. 6. Ctenarytaina spatulata Taylor, 1997. Terminália da fêmea. A, pigóforo, vista dorsal; B, pigóforo, vista látero-dorsal; C, detalhe do círculo de poros anais; D, ápice do pigóforo com setas lanceoladas; E, pigóforo, placa subgenital, valvas, vista lateral; F, valvas. Aa. abertura anal; Pg. pigóforo; Po. poro anal; Psg. placa subgenital; S. setas lanceoladas; $\mathrm{Vl}_{1}$. valva $1 ; \mathrm{Vl}_{2}$. valva 2; $\mathrm{Vl}_{3}$. valva 3.

encontra-se o ânus; na fêmea de C. spatulata o ânus abre-se numa área membranosa, do pigóforo, sem, no entanto, formar um tubo.

Baseando-se nas descrições apresentadas para $C$. spatulata (Taylor, 1997; Burckhardt et al., 1999) e nas observações do presente trabalho e comparando com a descrição de C. eucalypti (Tuthill, 1952; Burckhardt et al., 1999; Pinzón, 2002), pode-se afirmar que os adultos e as ninfas das duas espécies são muito semelhantes na forma, tamanho e no padrão de coloração, porém C. eucaypti apresenta uma coloração mais escura (marrom-escura a preto). O tubérculo pré-ocular de C. spatulata é proeminente enquanto que em $C$. eucalypti é achatado. A veia $\mathrm{Cu}_{1}$ em C. spatulata é mais longa e mais ou menos paralela a $\mathrm{M} \mathrm{e}$ em C. eucalypti é mais curta $\mathrm{e}$ curva. A segunda célula marginal em $C$. spatulata é mais longa e estreita do que em C. eucalypti. Os parâmeros em C. eucalypti não apresentam processos espiniformes na borda interna e o ápice do edeago é maior e mais largo.

\section{REFERÊNCIAS}

Borror, D. J., D. M. DeLong \& C. A. Triplehorn. 1981. Order Homoptera. In: An Introduction to the Study of Insects. 15 ed., Philadelphia, Saunders College Publishing, 308-343.

Burckhardt, D. 1994. Psylloid pests of temperate and subtropical crop and ornamental plants (Hemiptera, Psylloidea). A review. Trends in Agricultural Science Entomology 2: 173-186.

Burckhardt, D., D. L. Q. Santana, A. L. Terra, F. M. Andrade, S. R. C. Penteado, E. T. Iede \& C. S. Morey. 1999. Psyllid pests (Hemiptera:
Psylloidea) in South American eucalipt plantations. Bulletin de la Societè Entomologíque Suisse 72: 1-10.

Crawford, D. L. 1914. A monograph of the jumping plant-lice or Psyllidae of the new world. Bulletin United State National Museum 85: 186p., 30pls.

Hodkinson, I. D. 1974. The biology of the Psylloidea (Homoptera): a review. Bulletin of Entomological Research 64: 325-339.

Hodkinson, I. D. 1988. The Neartic Psylloidea (Insecta: Homoptera): an annoted check list. Journal of Natural History 22: 11791243.

Matsuda, R. 1965. Morphology and evolution of the insect thorax. Memoirs of the American Entomological Institute 4: 1-334.

Ossiannilson, F. L., M. Russel \& H. Weber. 1970. Homoptera. In: Tuxen, S. L. ed. Taxonomist's glossary of genitalia in insects. Copenhagen, Munksgaard, 359p.

Pinzón F., O. P., M. Guzmán C. \& F. Navas N. 2002. Contribución al conocimiento de la biologia, enemigos naturales y daños del pulgón del eucalipto Ctenarytaina eucalypti (Homoptera: Psyllidae). Revista Colombiana de Entomologia 28: 123-128.

Richards, O. W. \& R. G. Davies. 1977. Imm's General Textbook of Entomology: volume 2: Classification and Biology. 10 ed., London, Chapman and Hall, cap. 19.

Taylor, K. L. 1997. A new Australian species of Ctenarytaina Ferris and Klyver (Hemiptera: Psyllidae: Spondyliaspidinae) established in tree other countries. Journal of the Australian Entomology 36: $113-115$.

Tuthill, L. D. 1943. The psyllids of America North of Mexico (Psyllidae: Homoptera). Iowa State College Journal of Science 17: 443660.

Tuthill, L. D. \& K. L. Taylor. 1955. Australian genera of the family Psyllidae (Hemiptera: Homoptera). Australian Journal of Zoology 3: 22-257.

White, I. M. \& I. D. Hodkinson. 1985. Nymphal taxonomy and systematics of the Psylloidea (Homoptera). Bulletin British Museum Natural History Entomology 50: 153-301. 